\title{
O DIREITO DA CONCORRÊNCIA NO MERCOSUL ${ }^{1}$
}

Vinícius Klein

Mestrando em Direito das Relações Sociais na Universidade Federal do

Paraná, Bolsista da CAPES, Pesquisador do CNPq, Membro do NUPESUL e do Núcleo de Pesquisas em Direito Comercial da UFPR.

SUMÁRIO: Introdução; 1 Concorrência; 2 Concorrência e comércio internacional; 3 Principais objetivos dos tratados fundacionais do MERCOSUL; 4 Protocolo de Fortaleza; Conclusão; Referências bibliográficas.

\section{INTRODUÇÃO}

O presente artigo visa a promover uma análise sucinta do Protocolo de Fortaleza, estudo esse que será precedido necessariamente de considerações a respeito do direito da concorrência e do MERCOSUL (Mercado Comum do Cone Sul).

A análise do direito da concorrência passará pela sua noção e pelos seus conceitos fundamentais, quais sejam, concorrência instrumental, mercado relevante e regra da razão.

Em seguida o direito da concorrência será trabalhado na perspectiva do comércio internacional, de suma importância para situarmos o direito da concorrência no âmbito do MERCOSUL. Essa perspectiva procurará focar nos problemas existentes, notadamente quanto à competência.

Ainda uma análise rápida do MERCOSUL será necessária antes de adentrarmos ao objeto principal de estudo, que é o Protocolo de Fortaleza.

\section{CONCORRÊNCIA}

A concorrência pode ser conceituada na esteira do pensamento de RICARDO LUIS LORENZETTI como uma contrapartida ao direito de liberdade de escolha e tratamento eqüitativo do consumidor. Aliás, na opinião desse ilustre jurista argentino, trata-se de um microssistema próprio. ${ }^{2}$ Para MARIE-ANNE FRISON-ROCHE, ${ }^{3}$ o

1 Artigo produzido durante o primeiro semestre de 2002 no NUPESUL (Núcleo de Pesquisa em Direito Público do MERCOSUL), sob coordenação do Professor Doutor ROMEU FELIPE BACELLAR FILHO.

2 O autor define microssistema da seguinte maneira: “A explosão do Código produziu um fracionamento da ordem jurídica, semelhante ao sistema planetário. Criaram-se microssistemas jurídicos que, da mesma forma como os planetas, giram com autonomia própria, sua vida é independente; o Código é como sol, ilumina-os, colabora com as suas vidas, mas já não se pode incidir diretamente sobre eles". (LORENZETTI, Ricardo Luis. Fundamentos do direito privado. São Paulo: RT, 1998, p. 45)

3 FRISON-ROCHE, Marie Anne. L'état, le marché et les principes du droit interne et communautaire de a concourrence. Les Petites Affiches. Paris: Dalloz, n. 59, 1995, p. 4. 
direito da concorrência se constitui de nada mais que leis econômicas, às quais o direito empresta a sua normatividade. JOÃO MOTA DE CAMPOS, ${ }^{4}$ ao se perguntar qual é o conteúdo da concorrência no Mercado Comum da UE, afirma: "Trata-se de uma concorrência que tem por finalidade garantir a presença no mercado de um número suficiente de empresas independentes funcionando em condições adequadas a proporcionar aos consumidores e utilizadores uma razoável possibilidade de escolha". FABIO KONDER COMPARATO ${ }^{5}$ afirma que a regulamentação da concorrência surgiu da necessidade de que a liberdade de acesso ao mercado, decorrente do liberalismo econômico, não se transformasse em uma licença em prejuízo do próprio mercado e da concorrência. Adiante, afirma o autor que, no início, o fundamento da repressão à concorrência desleal foi a proteção à liberdade subjetiva dos concorrentes, ainda mais que hodiernamente o legislador preocupa-se com a proteção do próprio consumidor, e que a proteção aos interesses dos concorrentes só se faz em função da coletividade. ISABEL VAZ ${ }^{6}$ afirma que "o regime jurídico da concorrência compõe-se de um conjunto de normas e instituições que regulam as formas de aquisição do poder econômico e o seu exercício, segundo os valores adotados pela ordem jurídica”.

Essas definições nos levam a afirmar que a concorrência não é um fim em si mesma, pois busca ser um instrumento de determinados valores, valores esses perseguidos pela política econômica do Estado, que devem, conseqüentemente, ser condizentes com os princípios da ordem econômica. Ademais, a regulação da concorrência deriva do direito de escolha do consumidor, bem como da liberdade de iniciativa, que estaria sendo restringida se as distorções do mercado não fossem combatidas. Essas assertivas demonstram que, onde há mercado, deve haver proteção da concorrência; assim, se o MERCOSUL possui um mercado delimitado, decorrente da livre circulação de bens e capitais, devemos ter concorrência, e se temos um delineamento de um mercado mundial decorrente do comércio multilateral, poderíamos pensar na possibilidade de um direito da concorrência em âmbito mundial.

As assertivas acima nos levam a uma análise mais detalhada do tema. O presente estudo tem como objetivo ter uma visão da concorrência dentro do MERCOSUL. Para isso deve-se avançar um pouco além da mera definição do termo, para os objetivos das leis antitruste e os conceitos básicos. Primeiramente deve-se tratar do conceito de mercado relevante e, após, da noção de concorrência instrumental e da adoção, no direito americano, da regra da razão, conceitos esses que serão de fundamental importância para o prosseguimento do estudo.

A noção de mercado relevante é tida como muito elástica, podendo este ser definido, de acordo com PAULA FORGIONI, "como aquele em que se travam as relações de concorrência ou atua o agente econômico cujo comportamento está sendo

4 CAMPOS, João Mota de. Direito comunitário: o ordenamento econômico - o mercado interno da comunidade. Lisboa: Fundação Calouste Gulbenkian, v. III, 1991, p. 429.

5 COMPARATO, Fabio Konder. Concorrência Desleal. Revista dos Tribunais, n. 375, p. 30.

6 VAZ, Isabel. Direito econômico da concorrência. Rio de Janeiro: Forense, 1993, p. 262. 
analisado. Precisamos, ainda, distinguir o mercado relevante geográfico do mercado relevante material. O mercado relevante geográfico, conforme a mesma autora, é área onde se trava a concorrência relacionada à pratica que está sendo considerada restritiva, assim ele está ligado com a potencialidade de se afetar os hábitos dos consumidores. A verificação dessa potencialidade só é possível no caso concreto. Já o mercado relevante material parte das relações de concorrência mencionada na definição do conceito e pode ser obtido pela regra da possibilidade da substituição de um produto por outro, regra esta que surgiu no caso Du Pont ${ }^{7}$ apreciado pela Suprema Corte Americana, que asseverou: "O mercado relevante é composto de produtos que razoavelmente podem ser substituídos um pelo outro quando empregados nos fins para os quais são produzidos - levando em consideração o preço, a finalidade e a qualidade deles".

Para entendermos a regra da razão, devemos partir da seguinte da indagação: qual é o objetivo do direito da concorrência? Essa pergunta teve duas principais respostas, uma dada pela Escola de Harvard e outra pela Escola de Chicago. A primeira buscava a workable competion por meio da eliminação de todas as distorções excessivas do mercado. Já a Escola de Chicago tem sua filosofia expressa no livro de ROBERT H. BORK que possui o seguinte título: The Antitrust Paradox-a policy at war with itself. Ou seja, a busca pela preservação da concorrência não pode levar ao próprio combate a concorrência. Essa escola ganhou grande força nos anos $80 \mathrm{com}$ o governo de REAGAN e procurava diminuir a intervenção do Estado na economia. O debate na Europa para a noção de concorrência instrumental, ou seja, incluindo como um dos meios que o Estado possui para intervir na economia, fazendo parte do todo, qual seja, a política econômica geral do Estado. A versão européia da questão ganhou o debate no Brasil. Nesse contexto surge a regra da razão (rule of reason) nos Estados Unidos, em virtude da ausência, no Shreman Act $^{8}$, de mecanismos de flexibilização da disciplina antitruste, que era aplicada per se. A Suprema Corte a instituiu no caso Standart Oil Co. of New Jersey v. United States, afirmando que apenas as restrições não razoáveis à concorrência deveriam ser punidas.

Assim temos uma noção de mercado relevante, concorrência instrumental e regra da razão, o que nos será de grande utilidade a seguir.

\section{CONCORRÊNCIA E COMÉRCIO INTERNACIONAL}

A existência de um mercado, portanto, nos leva à necessidade de proteção da concorrência. Isso é bem visível tanto num mercado nacional quanto num mercado comum decorrente de um bloco econômico regional. O comércio internacional, entretanto, não fica imune a essa necessidade. Aliás o dito comércio internacional não é livre, pois não há proteção à livre concorrência por meio da punição do abuso do poder econômico, e assim a livre iniciativa resta desprotegida, o que possibilita a 
colocação de barreiras no acesso ao mercado. Caso o consenso internacional prime pela liberalização do comércio, deverá primar, também, por um fortalecimento da política da concorrência em nível global. Os conceitos atuais do direito da concorrência ligam a noção de mercado relevante à noção de jurisdição. Isso não acarreta problemas nos mercados nacionais e pode acarretar ou não num bloco, dependendo do seu sistema de controvérsias. Mas sob aspecto internacional, temos que buscar alternativas para uma regulação global do tema.

Esse problema, hodiernamente, encontra-se sob os auspícios da teoria dos efeitos ou da territorialidade objetiva (terminologia apresentada por JOÃO MOTA CAMPOS). ${ }^{9}$ Essa doutrina afirma que toda vez que o consumidor de um determinado país for afetado por uma prática contrária à disciplina da concorrência, o país possui legitimidade para analisar o ato. Essa construção teórica não tem sido suficiente para resolver o problema, já que esta teoria sofre de dois graves males: da concorrência de jurisdições e da ausência de qualquer harmonização de conceitos. Esse problema fica patente quando da análise de algumas legislações, por exemplo a americana, que não só se afirma competente naqueles casos em que o seu mercado sofre os efeitos da concentração empresarial, mas também para proteger empresas de sua nacionalidade, utilizando-se do conceito de imunidade soberana e de leis de bloqueio (blocking laws). ${ }^{10}$

O quadro acima desenhado é extremamente grave, dada a finalidade da política da concorrência tanto no âmbito nacional quanto no âmbito regional e a ligação entre a concorrência e o comércio internacional. A política da concorrência ao buscar a eficiência do mercado e conseqüentemente o bem-estar dos consumidores através de uma concorrência eficaz (workable competition) não pode entravar a intensificação do comércio mundial através de problemas de competência. A definição de regras a nível mundial evitaria também as incoerências comuns entre o direito antitruste e as demais políticas de defesa comercial, notadamente o direito antidumping.

Cabe ainda salientar a grande importância das concentrações empresariais entre empresas de diferentes países ou multinacionais e do efeito em vários mercados nacionais. Para ilustrar essa assertiva, pode-se citar os números do Departamento de Justiça dos EUA, nos quais $1 / 3$ de suas investigações contra cartéis envolveram cartéis internacionais. ${ }^{11}$

Cabe fazer uma indagação a respeito das soluções para o problema e qual o âmbito mais adequado, o bilateral, o regional ou o multilateral. O âmbito bilateral parece ser o mais factível, entretanto, é o mais limitado. O âmbito regional é mais propício à harmonização, mas ainda não produz soluções suficientes, apesar de provocar

9 CAMPOS, João Mota de. Direito comunitário: o ordenamento econômico - o mercado interno da comunidade. Lisboa: Fundação Calouste Gulbenkian, v. III, 1991.

10 Um exemplo claro disso é o processo antitruste americano contra a OPEP (Organização dos Países Produtores de Petróleo).

11 BALZAROTTI, Nora. Política de competencia internacional: cooperación, armonización y experiencia. Boletin Latino Americano de Competencia, Direção Geral IV,União Européia, n. 10, Parte 3, p. 4, jun. 2000 . 
uma diminuição dos conflitos. Uma possibilidade interessante parece ser a combinação de disciplinas regionais da concorrência e acordos bilaterais entre os blocos, o que tornaria abrangente o sistema e mais factível. Por fim, tem-se o âmbito multilateral, que seria aquele de mais difícil operacionalização, entretanto, o que poderia produzir soluções eficazes através de uma política de harmonização das diversas legislações. NORA BALZAROTTI ${ }^{12}$ traz alguns padrões mínimos para a discussão: 1. regras per se convivendo com regras de razão; 2 . a possibilidade dos particulares poderem invocar esses padrões nas cortes nacionais e a impossibilidade de se criarem exceções para as empresas exportadoras; 3 . adoção da cortesia positiva ou negativa dependendo do caso, e 4. ter como conteúdo os cartéis, abusos evidentes de posição dominante no mercado mundial e procedimento para a aprovação de movimentos de concentração empresarial de nível mundial.

Além de quantidade de acordos celebrados ultimamente, como por exemplo o dos EUA e União Européia, que trabalha com conceitos fundamentais para o estudo da harmonização das leis antitruste. Há também os MLATs (Tratados Bilaterais de Assistência Mútua) que são acordos bilaterais de assistência mútua celebrados entre os EUA e diversos países. Ainda temos o IAEAA (International Antitrust Enforcement Assistance Act), de 1994, nos EUA, que facilita, em certos casos, o intercâmbio de informações entre autoridades antitruste, além de outros acordos envolvendo.

A OMC exerce um papel importante a representar nesse aspecto, aliás uma possibilidade seria a de encarregar a referida organização internacional de promover a defesa da concorrência em nível mundial, o que levaria a solução dos conflitos antitruste para o seu sistema de solução de controvérsias, que será estudado como uma alternativa ao sistema de controvérsias do MERCOSUL. Em nível mundial, isso só seria possível com mutações nesse sistema, que outorguem os poderes necessários a esse organismo internacional. Seria necessário um acordo internacional assinado no âmbito da OMC que a outorgue poderes em matéria concorrencial, especialmente o poder investigatório e instrutório do procedimento. A esse respeito já se realizaram negociações na OMC, tendo a UE como principal defensora, entretanto, essas negociações encontram um óbice intransponível na negativa americana. A posição americana pode ser sintetizada em quatro princípios, trazidos por MARIA CECÍLIA DE ANDRADE SANTOS: ${ }^{13}$ I) a OMC não é o foro adequado para discutir problemas de concorrência internacional; II) a política da concorrência e a política comercial, apesar de possuírem pontos de contato, não devem estar reunidas sob a mesma perspectiva de análise, pois enquanto a primeira está centrada nas práticas privadas, a segunda dirige-se às medidas governamentais; III) preferência pela assistência técnica e pela celebração de acordos bilaterais; IV) atuação visando à garantia de livre acesso às empresas norte-americanas no mercado internacional.

12 Ibidem, idem, p. 9

13 SANTOS, Maria Cecília de Andrade. Concorrência. In: BARRAL, Welber (org.). O Brasil e a OMC: os interesses brasileiros e as futuras negociações multilaterais. Florianópolis: Diploma Legal, 2000, p. $482-483$ 


\section{PRINCIPAIS OBJETIVOS DOS TRATADOS FUNDACIONAIS DO MERCOSUL (TRATADOS FUNDACIONAIS DO MERCOSUL E OS PRINCÍPIOS DA GRADUALIDADE, FLEXIBILIDADE, RECIPROCIDADE E PACTA SUNT SERVANDA)}

O MERCOSUL foi instituído pelo Tratado de Assunção e objetiva um mercado comum do Cone Sul, tendo como Estados-partes Brasil, Argentina, Paraguai e Uruguai, além da Bolívia e do Chile como países associados. Atualmente o bloco vive uma alongada fase de transição para que se consolide a união aduaneira que ainda continua imperfeita, dada a limitação da TEC (Tarifa Exterior Comum).

O caráter intergovernamental do MERCOSUL nos leva aos princípios de direito internacional, e dentre eles temos o princípio do pacta sunt servanda, que pode ser tido como o princípio fundador do direito internacional. Assim os países são capazes de se obrigar através de tratados internacionais que devem ser cumpridos pelas partes, princípio este expresso na Convenção de Viena ${ }^{14}$ e no art. $8^{\circ}$, incisos $a$ e $b^{15}$ do Tratado de Assunção. Temos também o princípio da reciprocidade de direitos e das obrigações entre os Estados-partes expresso no art. $2^{\circ}$ do Tratado de Assunção. ${ }^{16}$

Além desses, o MERCOSUL também se pauta, segundo EDUARDO BIACCHI GOMES, ${ }^{17}$ pelos princípios da gradualidade e da flexibilidade e progressividade, expressos no Tratado de Assunção. A gradualidade está expressa no art. $6^{\circ}$ do Tratado de Assunção, ${ }^{18}$ decorrente da heterogeneidade socioeconômica dos Estados-partes, assim o processo de integração avança não de maneira abrupta, mas sim de acordo com decisões graduais visando à homogeneização e ao fortalecimento de todos os participantes. Já o princípio da flexibilidade, conjugado com o princípio da progressividade, decorre, mormente, da flexibilização das normas comerciais durante o período transitório, do seu caráter intergovernamental e da possibilidade de adesão ou denúncia a qualquer tempo. Esses princípios tornam a estrutura mais próxima das

14 "Art. 26. Todo o tratado em vigor obriga as partes e deve ser cumprido por elas de boa-fé."

15 "Art. $8^{\circ}$ Os Estados-partes se comprometem a preservar os compromissos assumidos até a data de celebração do presente Tratado, inclusive os acordos firmados no âmbito da Associação LatinaAmericana de Integração, e a coordenar suas posições nas negociações comerciais externas que empreendam durante o período de transição. Para tanto:

a) evitarão afetar os interesses dos Estados-partes nas negociações comerciais que realizem entre si até 31 de dezembro de 1994;

b) evitarão afetar os interesses dos demais Estados-partes ou objetivos do Mercado Comum nos acordos que celebrarem com outros países membros da Associação Latino-Americana de Integração."

16 Art. $2^{\circ} \mathrm{O}$ Mercado Comum estará fundado na reciprocidade de direitos e obrigações entre os Estadospartes.

17 GOMES, Eduardo Biacchi. Blocos econômicos e solução de controvérsias - uma análise comparativa a partir da União Européia e Mercosul. Curitiba: Juruá, 2001, p. 89.

18 Os Estados-partes reconhecem diferenças pontuais de ritmo para a República do Paraguai e para a República Oriental do Uruguai, que constam do Programa de Liberação Comercial (Anexo I). 
necessidades e demandas circunstanciais de cada participante, resguardando o seu interesse nacional.

Todos esses princípios, certamente, refletem no tratamento da política da concorrência pelo bloco. Os princípios da gradualidade e da flexibilidade não podem impedir, entretanto, a adoção de uma política de concorrência comum, decorrente da liberdade de circulação de capitais dentro do bloco, mas apenas produzir uma política cautelosa nesse âmbito, que respeite as opções de cada Estado-parte.

\section{PROTOCOLO DE FORTALEZA}

O direito da concorrência no MERCOSUL deriva do art. $4^{\circ}$ do Tratado de Assunção, que diz o seguinte: "Art. $4^{\circ}$ Nas relações com terceiros países, os Estadospartes assegurarão condições eqüitativas de comércio. Para tal fim, aplicarão suas legislações nacionais para inibir importações cujos preços estejam influenciados por subsídios, dumping ou qualquer outra prática desleal. Paralelamente, os Estados-partes coordenarão suas respectivas politicas nacionais com o objetivo de elaborar normas comuns sobre concorrência comercial'. (Grifos nossos)

O desiderato grifado foi implementado através do Protocolo de Fortaleza, que trata da defesa da concorrência no âmbito do MERCOSUL. Esse protocolo corresponde a Decisão $n^{\circ} 18 / 96$, do Grupo do Mercado Comum, tendo sido ratificado pelo Paraguai em 30 de outubro de 1997 e promulgado pelo Brasil através do Decreto $\mathrm{n}^{\circ} 3.602$, de 18 de setembro de 2000 , data em que começou a viger entre os dois países.

O referido protocolo, no primeiro capítulo, trata do seu âmbito de aplicação, adotando regra semelhante à utilizada pela União Européia no art. 85, caput, do Tratado de Roma, ${ }^{19}$ ao restringi-lo às medidas que tenham efeitos regionais, ou seja, sobre mais de um Estado. Assim, a aplicação do protocolo se restringe as práticas que tenham como mercado relevante mais de um Estado e que afetem o comércio entre os Estadospartes.

Após, o protocolo trata, no seu Capítulo II, dos atos que restringem a concorrência, adotando nesse particular noção semelhante à legislação brasileira, que elenca condutas de maneira exemplificativa e as pune apenas quando têm como efeito a distorção à concorrência. Essa disposição decorre do reconhecimento da licitude do poder econômico, punindo apenas o seu abuso.

O protocolo, nos dois capítulos seguintes, trata do procedimento e dos órgãos encarregados da sua aplicação. O procedimento envolve três órgãos: o Comitê de Defesa da Concorrência, a Comissão de Comércio do MERCOSUL e os órgãos nacionais de aplicação do protocolo. O comitê é formado pelos órgãos nacionais de aplicação do

19 “Art. 85. São incompatíveis com o Mercado Comum e proibidos todos os acordos entre empresas, todas as decisões de associações de empresas e todas as práticas concertadas que sejam susceptíveis de afectar o comércio entre os Estados-Membros e que tenham por objectivo ou efeito impedir, restringir ou falsear a concorrência o mercado comum, (...)" 
protocolo, sendo intergovernamental, ou seja, toma as suas decisões apenas por unanimidade. A iniciativa do projeto é exclusiva dos Estados-partes, que provocam o Comitê de Concorrência Nacional, através do seu órgão nacional, optando o comitê pelo prosseguimento ou não do processo; caso haja a opção do arquivamento, ele darse-á ad referendum da Comissão de Comércio. Além disso, o Comitê, da mesma maneira - ad referendum da Comissão -, em casos de extrema urgência, poderá aplicar medidas preventivas, sob pena de multa. A execução das medidas cabe ao órgão nacional. $\mathrm{O}$ poder investigatório - imprescindível para a análise de casos de concentração de capital, uma vez que ele é objeto de controle anterior pelo órgão de concorrência - é dividido entre o órgão nacional e o comitê. Cabe ao órgão nacional realizar a instrução do procedimento, entretanto, ele deve seguir os critérios definidos pelo comitê, tais como definição do mercado relevante e da sua estrutura econômica e os meios de prova a serem produzidos. O órgão nacional apresentará parecer a respeito do procedimento, que poderá ser aceito ou não pelo comitê, que definirá as infrações cometidas e as suas sanções, ad referendum da comissão, que se manifestará por meio de diretiva. Caso a comissão não chegue ao consenso, o Grupo Mercado Comum pronunciar-se-á mediante resolução, e, por fim, se o Grupo Mercado Comum não chegar ao consenso, o Estadoparte interessado deverá agir de acordo com o Protocolo de Brasília de Solução de Controvérsias. O protocolo inclui, ainda, a obrigação de cooperação entre os órgãos nacionais dos países envolvidos, que poderão solicitar um pronunciamento da comissão caso haja dúvida na aplicação do presente procedimento.

O protocolo traz ainda um compromisso de cessação, similar ao compromisso de desempenho previsto no art. 54 da Lei ${ }^{\circ} 8.894 / 94$, brasileira, que elide a imposição de multas pelos atos praticados se os infratores se comprometerem com certas condutas. A celebração no MERCOSUL caberá ao Comitê de Defesa da Concorrência, ad referendum da Comissão de Comércio do MERCOSUL. Já a execução caberá ao órgão nacional de aplicação do protocolo.

Em relação às sanções, o protocolo as prevê no seu art. 28 e expressamente dispõe no art. 31 que as controvérsias serão solucionadas no âmbito dos protocolos de Brasília e Ouro Preto.

CALIXTO SALOMÃO ${ }^{20}$ observa que o protocolo, ao contrário da legislação pátria e argentina, não prevê regra sobre o controle das concentrações, o que causa apreensão, dada a importância da temática. Entretanto, o seu art. $7^{\circ}$ prevê num prazo de dois anos, o que pode proporcionar um certo alento, pois, se falta a concretização, pelos menos tem-se o direcionamento.

Por fim, o protocolo, a promover num prazo de dois anos a harmonização das legislações nacionais e as integrar às demais medidas de defesa comercial, ${ }^{21}$ fortalece a posição do bloco e do Brasil para negociar a adoção pela OMC de regras de

20 SALOMÃO FILHO, Calixto. Direito concorrencial - as estruturas. 2. ed. São Paulo: Malheiros, 2002, p. 49.

21 Tais como antidumping, ajudas estatais e setores públicos. 
concorrência, política essa que favoreceria o Brasil, objeto, certamente, de vários cartéis internacionais.

\section{CONCLUSÃO}

O direito da concorrência no MERCOSUL foi materializado no Protocolo de Fortaleza, que carece, ainda, de concretização, entretanto, trata-se, indubitavelmente, de um passo a frente no tratamento do tema no referido bloco, tanto é verdade que o processo de integração é pautado pelos princípios da flexibilidade e gradualidade. $\mathrm{O}$ método de construtividade adotado tem consequiências para a disciplina da concorrência, entretanto, a aplicação da política de concorrência só será valida enquanto apta a garantir a livre iniciativa dentro do bloco, mesmo que dentro dos atuais limites decorrentes da estrutura do MERCOSUL e das diferenças econômicas entre os sócios.

O Protocolo de Fortaleza, ao criar um procedimento próprio do MERCOSUL de defesa da concorrência, preenche uma necessidade proeminente do bloco, entretanto, ele deverá ser aperfeiçoado com a harmonização das legislações dos Estados-partes, bem como avançar para as demais políticas de defesa comercial, protegendo a liberdade de circulação de bens e serviços e mormente a liberdade de iniciativa, ou seja, a ausência de impedimentos para a acessibilidade do mercado pelos agentes econômicos.

\section{REFERÊNCIAS BIBLIOGRÁFICAS}

ACCIOLY, Elizabeth. Mercosul e União Européia: estrutura jurídico-institucional. 2. ed. Curitiba: Juruá, 2000.

BALZAROTTI, Nora. Política de competencia internacional: cooperación, armonización y experiencia. Boletin Latino Americano de Competencia, Direção Geral IV, União Européia, n. 10, parte 3, jun. 2000.

BARRAL, Welber (org.). O Brasil e a OMC: os interesses brasileiros e as futuras negociações multilaterais. Florianópolis: Diploma Legal, 2000.

BIENNAYMÉ, Alain. Principes de concurrence. Paris: Economica, 1998.

BORK, Robert H. The antitrust paradox - a policy at war with itself. Free Press, 1995.

BRAULT, Dominique. Droit et politique de la concurrence. Paris: Economica, 1997.

CASELA, Paulo Borba (org.). Contratos internacionais e direito econômico no MERCOSUL. São Paulo: LTr, 1996.

CAMPOS, João Mota de. Direito comunitário: o ordenamento econômico - o mercado interno da comunidade. Lisboa: Fundação Calouste Gulbenkian, v. III, 1991.

COMPARATO, Fabio Konder. Concorrência Desleal. Revista dos Tribunais, n. 375, p. 29-35.

FARIA, Werter R. Defesa da concorrência no Mercosul. Brasília: Senado Federal, 1991.

FRISON-ROCHE, Marie Anne. L'état, le marché et les principes du droit interne et communautaire de la concourrence. Les Petites Affiches. Paris: Dalloz, n. 59, 1995, p. 4.

FORGIONI, Paula A. Os fundamentos do antitruste. São Paulo: Revista dos Tribunais, 1998.

GOMES, Eduardo Biacchi. Blocos econômicos e solução de controvérsias - uma análise comparativa a partir da União Européia e Mercosul. Curitiba: Juruá, 2001. 
GRAU, Eros Roberto. A ordem econômica na Constituição de 1988 - interpretação e crítica. São Paulo: Revista dos Tribunais, 1990.

LORENZETTI, Ricardo Luis. Fundamentos do direito privado. São Paulo: RT, 1998.

SALOMÃO FILHO, Calixto. Direito concorrencial - as estruturas. 2. ed. São Paulo: Malheiros, 2002.

VAZ, Isabel. Direito econômico da concorrência. Rio de Janeiro: Forense, 1993. 